\title{
QUEEN'S
UNIVERSITY
BELFAST
}

\section{Long-term hydrolytically stable bond formation for future membrane- based deep ocean microfluidic chemical sensors}

Tweedie, M., Sun, D., Ward, B., \& Maguire, P. D. (2019). Long-term hydrolytically stable bond formation for future membrane-based deep ocean microfluidic chemical sensors. Lab on a Chip, 19(7), 1287-1295.

https://doi.org/10.1039/C9LC00123A

\section{Published in:}

Lab on a Chip

\section{Document Version:}

Peer reviewed version

Queen's University Belfast - Research Portal:

Link to publication record in Queen's University Belfast Research Portal

\section{Publisher rights}

(C) 2019 The Royal Society of Chemistry.

This work is made available online in accordance with the publisher's policies. Please refer to any applicable terms of use of the publisher.

\section{General rights}

Copyright for the publications made accessible via the Queen's University Belfast Research Portal is retained by the author(s) and / or other copyright owners and it is a condition of accessing these publications that users recognise and abide by the legal requirements associated with these rights.

Take down policy

The Research Portal is Queen's institutional repository that provides access to Queen's research output. Every effort has been made to ensure that content in the Research Portal does not infringe any person's rights, or applicable UK laws. If you discover content in the Research Portal that you believe breaches copyright or violates any law, please contact openaccess@qub.ac.uk. 


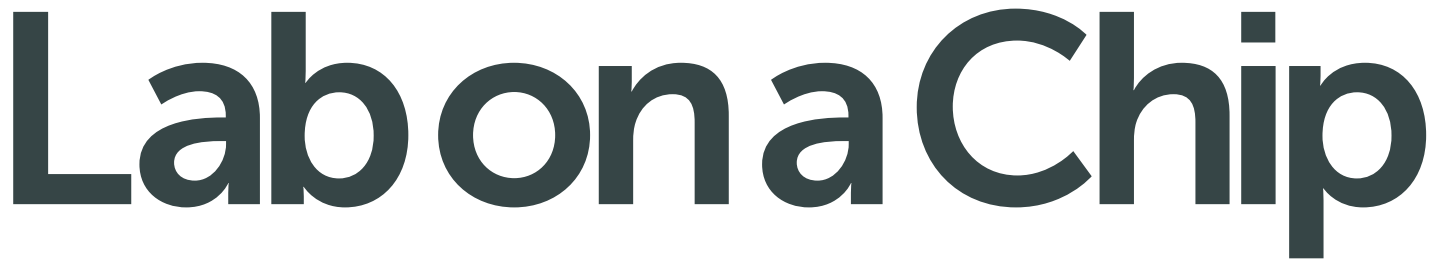

\section{Accepted Manuscript}

This article can be cited before page numbers have been issued, to do this please use: M. Tweedie, D. Sun, B. Ward and P. Maguire, Lab Chip, 2019, DOI: 10.1039/C9LC00123A.
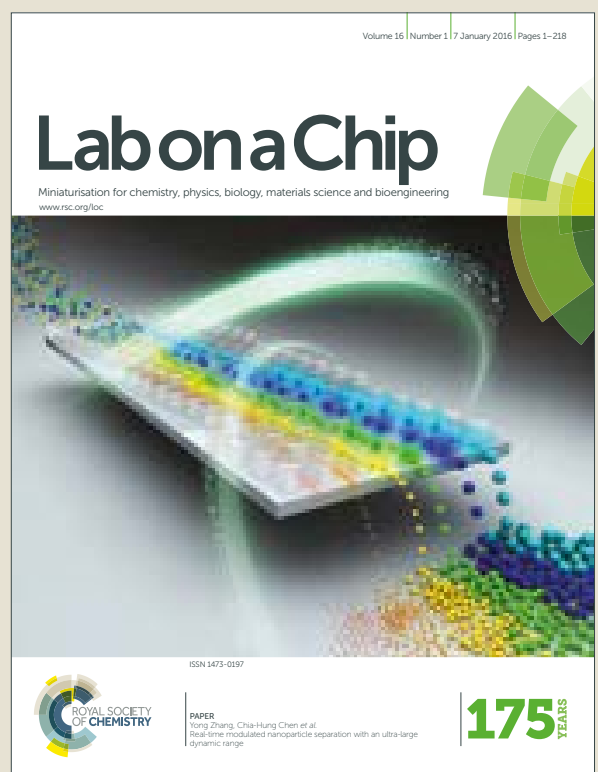

This is an Accepted Manuscript, which has been through the Royal Society of Chemistry peer review process and has been accepted for publication.

Accepted Manuscripts are published online shortly after acceptance, before technical editing, formatting and proof reading. Using this free service, authors can make their results available to the community, in citable form, before we publish the edited article. We will replace this Accepted Manuscript with the edited and formatted Advance Article as soon as it is available.

You can find more information about Accepted Manuscripts in the author guidelines.

Please note that technical editing may introduce minor changes to the text and/or graphics, which may alter content. The journal's standard Terms \& Conditions and the ethical guidelines, outlined in our author and reviewer resource centre, still apply. In no event shall the Royal Society of Chemistry be held responsible for any errors or omissions in this Accepted Manuscript or any consequences arising from the use of any information it contains. 


\section{Lab on a Chip}

\section{Long-term hydrolytically stable bond formation for future membrane-based deep ocean microfluidic chemical sensors.}

Received 00th January 20xx, Accepted 00th January 20xx

DOI: $10.1039 / x 0 x \times 00000 x$

www.rsc.org/

\author{
M. Tweedie*a, D. Sun ${ }^{b}$, B. Wardc, P.D. Maguire ${ }^{a}$
}

\begin{abstract}
Future ocean profiling of dissolved inorganic carbon and other analytes will require miniaturised chemical analysis systems based on sealed gas membranes between two fluid channels. However, for long-term deployment in the deep ocean at high pressure, the ability to seal incompatible materials represents an immense challenge. We demonstrate proof of principle for high strength bond sealing. We show that Polydimethylsiloxane (PDMS) is a preferred membrane material for rapid $\mathrm{CO}_{2}$ transfer, without ion leakage, and report long-term stable bonding of thin PDMS membrane films to inert thermoplastic Poly(methyl methacrylate) (PMMA) patterned manifolds. Device channels were filled with $0.01 \mathrm{M} \mathrm{NaOH}$ and subjected to repeated tape pull and pressure - flow tests without failure for up to six weeks. Bond formation utilised a thin coating of the aminosilane Bis-[3-TriMethoxySilylPropyl]Amine (BTMSPA) conformally coated onto PMMA channels and surfaces and cured. All surfaces were subsequently plasma treated and devices subject to thermocompressive bond annealing. Successful chemically resistant bonding of membrane materials to thermoplastics opens the possibility of remote environmental chemical analysis and offers a route to float-based depth profiling of dissolved inorganic carbon in the oceans.
\end{abstract}

\section{Introduction}

The concentration of carbon dioxide in the atmosphere has increased by over $40 \%$ since pre-industrial times leading to significant global warming ${ }^{1}$ with predictions of major climate change. In the past, the oceans have absorbed up to $30 \%$ of the atmospheric $\mathrm{CO}_{2},{ }^{2}$ but this capability is saturating, possibly leading to much more serious consequences than predicted so $\mathrm{far}^{3}$. Understanding the ocean $\mathrm{CO}_{2}$ system is of fundamental importance to climate change models yet $\mathrm{CO}_{2}$ continues to be chronically undersampled in both space (including depth profiles) and time; current $\mathrm{CO}_{2}$ observations are almost exclusively limited to the surface and use large sensors attached to expensive research vessels. ${ }^{4}$ Developing robust miniature lab on chip chemical sensors and profilers, suitable for long term deployment in harsh environments, presents a serious challenge for microfluidics fabrication. ${ }^{5}$ It is not yet clear that such a grand challenge can be overcome. ${ }^{6,7}$ In this work, we report on longterm and stable membrane sealing to a thermoplastic manifold where the seal is chemically resistant and can tolerate high pressure cycling. This represents the key immediate challenge in developing a

a. NIBEC, Ulster University, Belfast, Northern Ireland, BT37 OQB.

b. School of Mechanical and Aerospace Engineering, Queen's University of Belfast, BT9 $5 \mathrm{AH}$.

c. School of Physics and Ryan Institute, National University of Ireland, Galway, Republic of Ireland. membrane-based microfluidics approach to conductimetric $\mathrm{CO}_{2}$ detection. Since such a device relies on molecular gas exchange between two electrolyte filled chambers, we examine both the $\mathrm{CO}_{2}$ gas permeability and the ion transport resistance of a range of standard polymer-based synthetic membrane materials. Resistance to high strength alkali is required of the bond and ocean $\mathrm{CO}_{2}$ depth profiling will also require multiple closely spaced microchannels. Isolation between neighbouring microchannel gas and ion components is critical for detector accuracy. We therefore test the bond resilience under strong alkali conditions in multi-channel structures to determine bond lifetime and failure as well as interchannel leakage.

The ocean $\mathrm{CO}_{2}$ system is typically characterized by measuring two or more of the four canonical "master variables": total dissolved inorganic carbon $\left(\mathrm{C}_{\mathrm{T}}\right)$, total alkalinity $\left(\mathrm{A}_{\mathrm{T}}\right)$, partial pressure of $\mathrm{CO}_{2}$ $\left(\mathrm{pCO}_{2}\right)$, and acidity $(\mathrm{pH})$. Unfortunately, both $\mathrm{pCO}_{2}$ and $\mathrm{pH}$ are very sensitive to temperature and pressure, unlike $C_{T}$ and $A_{T} ;{ }^{8}$ hence robust autonomous measurements of the latter two are preferred but have yet to be realized. ${ }^{9}$ The Argo float network ${ }^{10}$, consisting of a global array of $>3,000$ untethered battery-operated floats, is a sophisticated and ambitious project to enhance the spatiotemporal resolution of observations and at present it enables continuous monitoring of ocean salinity and temperature depth profiles. ${ }^{10}$ This float array infrastructure is eagerly awaiting new autonomous chemical sensor technology and it provides clear constraints for 
device footprint, volume, power consumption and long term environmental stability with high pressure operational cycling up to 200 atm. $^{5}$

Microfluidic ocean-relevant chemical sensors have received limited attention. Research in this area is still in its infancy and efforts have concentrated on shallow depth detection of phosphate, ${ }^{11-13}$ nitrates/nitrites ${ }^{14,15}$, and $\mathrm{pH}^{16}$ by colorimetric techniques. Also bioluminescence ${ }^{17,18}$ and chemiluminescence ${ }^{19}$ approaches have been explored. It is not clear that autonomous $C_{T}$ measurements and profiling will be possible via similar approaches, although membrane-based microfluidics coupled with optical methods would be beneficial in other sensor applications. Autonomous $\mathrm{CO}_{2}$ observations have been limited mainly to surface $\mathrm{pCO}_{2}$ via IR and optical techniques ${ }^{20-22}$ or spectrophotometry profilers..$^{23,24}$ Recently, autonomous measurements of $C_{T}$ have been reported via spectrophotometry ${ }^{25,26}, \mathrm{NDIR}^{27}$, and mass spectrometry. ${ }^{28}$ These are large systems with significant power requirements and unlikely candidates for miniaturisation. Sayles and Eck report autonomous $C_{T}$ measurements from a fixed mooring using a membrane-based device. ${ }^{29}$ This employs the conductimetric $C_{T}$ measurement method of Hall and Aller whereby acidified seawater liberates the dissolved $\mathrm{CO}_{2}$ across the membrane, reducing the conductivity of $\mathrm{NaOH}$ on the receiving side. ${ }^{30}$ Plant et al. used a miniaturised custom membrane exchange cell for autonomous conductimetric shallow water measurements of $\mathrm{NH}_{4}{ }^{31}$ Although the device used simple short-term compression sealing of the membrane, it illustrates a route to ultimate miniaturisation provided suitable long-term membrane sealing can be achieved. While membrane-based microfluidics has received attention recently, gas exchange between liquids requires non-porous and ion-impermeable membrane materials for $\mathrm{CO}_{2}$ detection. ${ }^{26,32,33}$ The permanent sealing of such materials to prevent capillary-flow induced hydrolytic attack and/or cross-contamination between multiple depth samples, remains a major challenge.

Argo floats remain at depth for long periods (days) between measurement and signal transmission to satellite, and since $C_{T}$ is independent of temperature and pressure, $C_{T}$ profiling may be possible by collecting and storing multiple samples during float descent followed by chemical analysis at depth, where long equilibration times would be available. We have recently reported the fabrication of a robust thermoplastic prototype manifold for deep ocean sample collection and storage. ${ }^{32}$ The use of PDMS as both manifold and membrane material would lead to $\mathrm{CO}_{2}$ crosscontamination between channels. Integration with a membrane exchange cell therefore requires the fabrication of a multi-channel and multi-layer bonded stack which includes a thermoplastic membrane film - thermoplastic sandwich.

The Argo floats have an external diameter of $170 \mathrm{~mm}$. An example plan view schematic of such a microfluidic device, of a suitable size to fit the Argo float, is shown in Fig. 1, and contains, firstly, a valved storage channel section to hold seawater samples taken from different depths. Ultimately 100 storage channels would be required in order to achieve $20 \mathrm{~m}$ depth resolution. At the analysis stage, the samples would be drawn, one at a time, through the precision acid

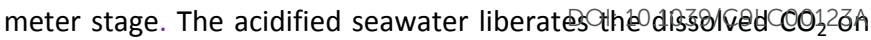
reaching the double-layer diffusion cell, with a PDMS gas permeable membrane separating the sample and reagent $(\mathrm{NaOH})$ liquid layers. The free $\mathrm{CO}_{2}$ on the sample side diffuses through the membrane into $\mathrm{NaOH}$ on the other side, reducing the conductivity, as measured by a pair of in-channel electrodes.

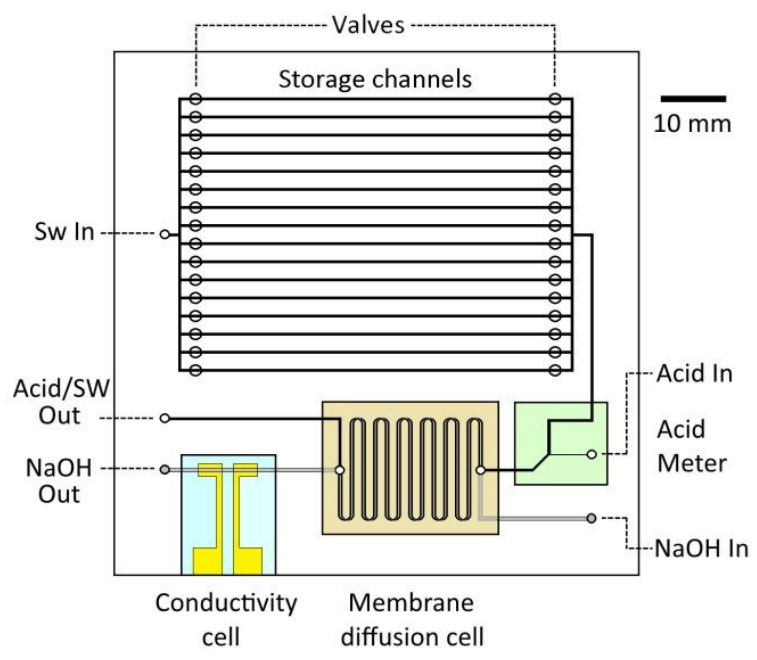

(a)

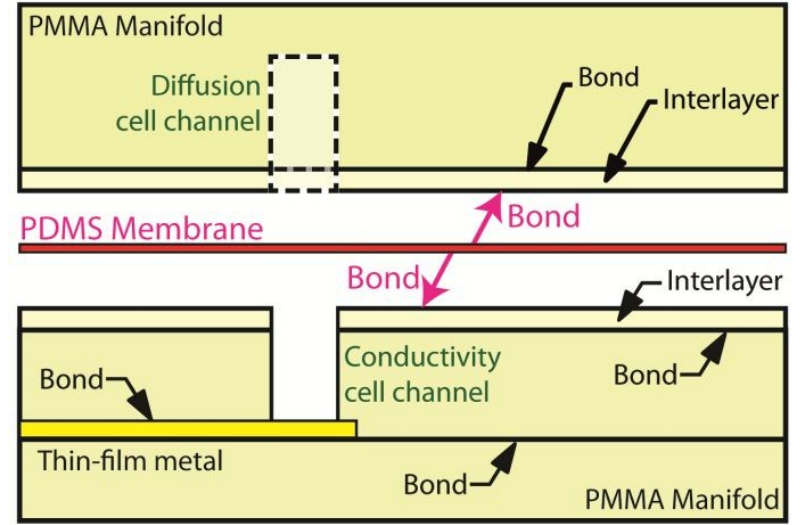

(b)

Fig. 1 (a) Schematic plan view of prospective SW (seawater) storage and $\mathrm{CO}_{2}$ diffusion analysis device, scaled to fit Argo float. Ultimately 100 storage channels, with addressable non-hydraulic valves will be required in an integrated $100 \times 100 \mathrm{~mm}$ manifold also containing acid meter, diffusion cell and conductivity cell subunits. (b) schematic cross- section of seven-layer membrane device, illustrating the $\mathrm{SW}$ sample and $\mathrm{CO}_{2}$ measurement cells separated by a thin PDMS membrane.

The membrane materials will need to cover the full manifold area and bond to top and bottom thermoplastic manifolds with patterned microchannels. The channel pitch, which determines the available bonding area to maintain sample isolation will be $<200 \mu \mathrm{m}$. PDMS sheet bonds to itself after oxygen plasma or corona treatment, or using uncured or partially cured PDMS liquid interlayers, relatively easily. ${ }^{43}$ However, the hydrophobicity of high permeability 
membrane materials, such as Polydimethylsiloxane (PDMS), seriously inhibits irreversible bonding to chemically inert thermoplastics e.g. Poly(methyl methacrylate) (PMMA) or Cyclic Olefin Copolymer (COC). Numerous approaches have been attempted including thermal, solvent, sol-gel, plasma, adhesive or lamination but with limited success. Double-sided adhesive tape has been demonstrated to achieve bonding between PDMS and PMMA but the tape interlayer is impermeable to $\mathrm{CO}_{2} \cdot{ }^{44} \mathrm{PDMS}$ has also been used as an adhesive layer between a solid PMMA part and PMMA with channels, but this does not lend itself to the creation of a suspended PDMS membrane. ${ }^{45}$ Plasma immobilised aminosilane linker layers have offered a potential route to sealing by producing activated groups suitable for bonding to PDMS. ${ }^{34-36,46}$ In anhydrous solvents, aminosilanes tend to bond via the amine group onto the thermoplastic surface, leaving the Si end uppermost, facilitating Si$\mathrm{O}-\mathrm{C}$ bond formation to PDMS. Subsequent curing produces a strongly interlinked molecular structure. However, such bonds have been restricted to small areas ${ }^{37}$ or to plastics such as PC and PET. ${ }^{38}$ More importantly, Si-O-C bonds have limited hydrolytic resistance, a critical requirement for membrane-based chemical detection. ${ }^{39}$ The use of monopodal aminosilanes, e.g. APTES (AminoPropylTriethoxySilane) or some bipodal silanes, e.g. BTMSPA (Bis-[3-TriMethoxySilyIPropyl]Amine) have been investigated. Lee and Ram [39] investigated hydrolytic stability of PC - PDMS bonding using aminosilanes and observed some improvement in bond stability to $\mathrm{NaOH}$ attack. However, given their device structure and intended applications, the stressed bond is not exposed to the $\mathrm{NaOH}$ itself and therefore the hydrolytic performance of the bond within a dual channel structure is not demonstrated. With a $C_{T}$ membrane exchange cell, bonds on either side of the membrane would be in continuous contact with acids $(\sim \mathrm{pH} 2)$ and bases $(\sim \mathrm{pH} 12)$. The hydrolytic stability of such continually exposed PDMS-thermoplastic bonds has not been investigated. In this work we report high strength bonding of PDMS to PMMA with hydrolytic stability over many months. Large area test structures with high pattern densities are used to simulate the restricted bond area available in multi-channel devices and cross-contamination via inter-channel leakage is evaluated.

\section{Materials and Methods}

Gas permeable PDMS (50 and $125 \mu \mathrm{m}$ thickness), as well as porous PTFE (63 $\mu \mathrm{m}$ thickness), and semi-permeable PS, PP, PC and LDPE films (between 20 and $125 \mu \mathrm{m}$ thickness), were purchased from Goodfellow Cambridge Ltd. These were required for comparative testing of ion leakage through the films and, where necessary, $\mathrm{CO}_{2}$ transfer. Semi-permeable materials, typically, have a $\mathrm{CO}_{2}$ permeability in the range $1-10\left(x 10^{-13} \mathrm{~cm}^{3} \mathrm{~cm} \mathrm{~cm}^{-2} \mathrm{~s}^{-1} \mathrm{~Pa}^{-1}\right)$, compared to $2500\left(\times 10^{-13} \mathrm{~cm}^{3} \mathrm{~cm} \mathrm{~cm}^{-2} \mathrm{~s}^{-1} \mathrm{~Pa}^{-1}\right)$ for permeable PDMS Aminosilanes, APTES (Amino Propyl TriMethoxy Silane), BTMSPA (Bis-[3-TriMethoxySilylPropyl]Amine), and other chemicals (IPA, $0.1 \mathrm{M} \mathrm{NaOH}, 0.1 \mathrm{M} \mathrm{HCl}$, and $0.1 \mathrm{M} \mathrm{Na}_{2} \mathrm{HCO}_{3}$ ) were sourced from Sigma Aldrich UK Ltd. Anhydrous IPA (99.5\%) was used for cleaning non-machined substrates, and PDMS and thermoplastic polymer

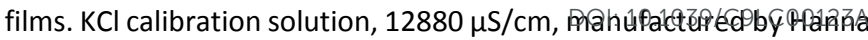
Instruments Inc., was used for testing ion leakage for various membranes.

For testing $\mathrm{CO}_{2}$ transfer through membranes, $\mathrm{HCl}$ and $\mathrm{Na}_{2} \mathrm{HCO}_{3}$ were used to create a high concentration $\mathrm{TCO}_{2}$ solution, so that $\mathrm{CO}_{2}$ molecules would pass through the test membrane, reacting with $\mathrm{NaOH}$ on the opposing side. The $\mathrm{HCO}_{3}{ }^{-}$bicarbonate ion so created has a lower ionic conductivity than the $\mathrm{OH}^{-}$ion, and, therefore, the conductivity drops according to the amount of $\mathrm{CO}_{2}$ transferred. Mixing $5 \mathrm{~mL}$ of $100 \mathrm{mM} \mathrm{HCl}$ with $15 \mathrm{~mL}$ of $100 \mathrm{mM} \mathrm{Na}_{2} \mathrm{HCO}_{3}$, creating $\sim 25 \mathrm{mM} \mathrm{TCO}_{2}$, ensured the reaction of $\mathrm{CO}_{2}$ with $\mathrm{NaOH}$ reached saturation. For testing ion leakage and $\mathrm{TCO}_{2}$ transfer, test cells of 50 $\mathrm{mm}$ outer diameter, and $17 \mathrm{~mm}$ inner diameter, were machined in Perspex rod, where the membrane was clamped between the two halves, Fig. 2. In one variant, a conductivity probe was sealed in place through a hole in the base of one side, for continuous conductivity monitoring. A Metrohm 712 conductivity probe and meter were used in temperature-compensated mode, where a standard correction of $2 \% /{ }^{\circ} \mathrm{C}$ is automatically applied by the instrument, using the temperature measured by the probe tip. The centre of the probe was $\sim 15 \mathrm{~mm}$ below the membrane. For ion leakage tests, $\mathrm{KOH}$ salt $(12880 \mu \mathrm{S} / \mathrm{cm})$ is placed in one half of the cell, with DI water on the other side of membrane. For $\mathrm{TCO}_{2}$ transfer tests, the acidified $\mathrm{Na}_{2} \mathrm{HCO}_{3}$ solution was placed on one side with $9.1 \mathrm{mM} \mathrm{NaOH}$ solution on the other.

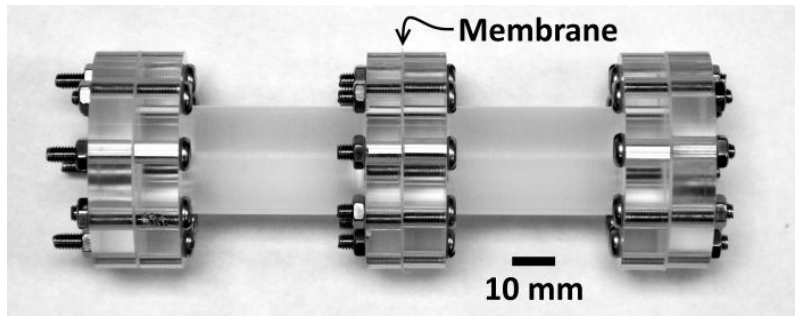

Fig. 2 Symmetrical test cell for ion leakage and TCO2 transfer, with various membrane materials, centrally clamped.

Short term chemical resistance tests of PDMS membranes bonded to PMMA used $\sim 1 \mathrm{M} \mathrm{NaOH}$ (Microposit 351, Chestech Ltd.). For longer term tests, $0.1 \mathrm{M} \mathrm{NaOH}$ (Sigma Aldrich) was diluted to $\sim 0.01 \mathrm{M}$ solution using DI water. Plasma surface treatments were obtained via a BD20 AVC (40 W) corona device with a stainless steel linear element (Electro Technic Products Inc.). ${ }^{41,42}$ NanoPorts and microfluidic accessories (Upchurch, IDEX Corp.) were attached to fluidic devices using epoxy adhesive. Square cross-section channels ( 0.5 - $1 \mathrm{~mm}$ wide) were milled into PMMA manifolds using a Modela MDX20 micromill (Roland DG) and substrates were subsequently cleaned using DI water and/or IPA. Some substrates were milled flat, channels milled, sonicated in IPA/DI water to remove residual milling coolant, and a thermocompression vacuum bonder (EVG52OHE) was then used to flatten the milling marks, reducing the channel depths to $0.3-0.5 \mathrm{~mm}$, and widths by $25 \%$. After further IPA/DI sonication, 
these were dried in vacuum for 2 hours before use. Substrates of PMMA with microchannels were corona treated for $5 \mathrm{~s} \mathrm{~cm}^{-2}$, at a height of 3-6 mm. Aminosilanes were deposited on PMMA immediately after corona treatment, using one of four methods, see Table 1. Vapour deposition in air was carried out at a height of $\sim 3 \mathrm{~mm}$, giving a non-visible ultrathin layer. Thicker silane layers were applied manually and cured at high humidity inside a glass evacuated desiccator placed in a convection oven for $1-2$ hours. With the oven set point at $120^{\circ} \mathrm{C}$, the internal temperature in the desiccator reached $80^{\circ} \mathrm{C}$. Silane films were corona treated for $1-3$ mins, depending on area, just prior to a 30s corona activation of the PDMS. The treated PDMS was then joined immediately to the activated silane-coated PMMA.

\begin{tabular}{|l|l|}
\hline & Silane application \\
\hline S1 & Silane vapour in air \\
\hline S2 & Silane vapour under vacuum \\
\hline S3 & Immersion in dilute silane solution \\
\hline S4 & Manual (dilute solution) \\
\hline S5 & Manual (aged solution) \\
\hline
\end{tabular}

\section{Table 1 Silane application methods}

The PDMS-PMMA substrates were subsequently annealed in an EVG520 bonder to form the bond (with the exception of an oven anneal test case). A uniform mechanical force was applied in vacuum at elevated temperature. The upper pressure plate temperature overshoots on ramp up by $\sim 30^{\circ} \mathrm{C}$ before settling to the preset value, whereas the lower plate rises more slowly with little overshoot. However, final stage PDMS separation from the top plate was easier than from a glass plate needed to cover the vacuum grooves in the base plate. PDMS distortion over channels after thermo-compressive bond anneal was significantly less for the $50 \mu \mathrm{m}$ compared to the 125 $\mu \mathrm{m}$ thickness films. The temperature hold stage was set below the $T_{g}$ of PMMA $\left(105^{\circ} \mathrm{C}\right)$, to limit plastic reflow at elevated pressure in the shallow microfluidic channels. The applied pressure and vacuum together help remove microbubbles between the layers. Multiple bonding experiments were performed using thin and thick layer aminosilane layers. Tape pull testing (low residue 3M Scotch Magic tape), well-known for rapid bond assessment, was carried out after channels were filled with fluid. ${ }^{47-49}$ The bond anneal variations are listed in Table 2.

\begin{tabular}{|c|c|c|c|}
\hline No & \multicolumn{2}{|r|}{ PDMS position } & $\begin{array}{l}\text { Bond anneal } \\
30 \mathrm{~min}\end{array}$ \\
\hline \multirow[t]{2}{*}{ B1 } & \multirow[t]{2}{*}{ Top } & $T_{\text {initial }} 110^{\circ} \mathrm{C}$ & \multirow[t]{2}{*}{$200 \mathrm{~N}-10,000 \mathrm{~N}$} \\
\hline & & $\mathrm{T}_{\text {final }} 80^{\circ} \mathrm{C}, 15 \mathrm{~min}$ & \\
\hline B2 & Bottom & $80^{\circ} \mathrm{C}$ & $200 \mathrm{~N}-10,000 \mathrm{~N}$ \\
\hline \multirow[t]{2}{*}{ B3 } & \multirow[t]{2}{*}{ Top } & $\mathrm{T}_{\text {initial }} 110^{\circ} \mathrm{C}$ & \multirow[t]{2}{*}{$200 \mathrm{~N}-10,000 \mathrm{~N}$} \\
\hline & & $\mathrm{T}_{\text {final }} 80^{\circ} \mathrm{C}, 15 \mathrm{~min}$ & \\
\hline \multirow[t]{2}{*}{ B4 } & \multirow[t]{2}{*}{ Top } & $\mathrm{T}_{\text {initial }} 110^{\circ} \mathrm{C}$ & \multirow{2}{*}{$\begin{array}{l}400 \mathrm{~N} \text { at } 25^{\circ} \mathrm{C} \\
0 \mathrm{~N} \text { at } 80^{\circ} \mathrm{C}\end{array}$} \\
\hline & & $\mathrm{T}_{\text {final }} 80^{\circ} \mathrm{C}, 15 \mathrm{~min}$ & \\
\hline B5 & Top & $\mathrm{T}_{\text {initial }} 110^{\circ} \mathrm{C}$ & $0 \mathrm{~N} .80^{\circ} \mathrm{C}$ \\
\hline
\end{tabular}

\begin{tabular}{|c|c|c|c|}
\hline & & $T_{\text {final }} 80^{\circ} \mathrm{C}, 15 \mathrm{~min}$ & \\
\hline \multirow[t]{2}{*}{ B6 } & \multirow[t]{2}{*}{ Top } & $\mathrm{T}_{\text {initial }} 110^{\circ} \mathrm{C}$ & \multirow[t]{2}{*}{ 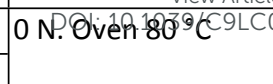 } \\
\hline & & $\mathrm{T}_{\text {final }} 80^{\circ} \mathrm{C}, 15 \mathrm{~min}$ & \\
\hline
\end{tabular}

Table 2. Bond anneal methods.

Various process paths were assessed, and a flowchart summarising the process flow and options is given in Fig. 3. For thick silane layers, the high humidity cure was optimal at an internal temperature of 80 ${ }^{\circ} \mathrm{C}$, in the vacuum dessicator containing the PMMA piece and DI water.

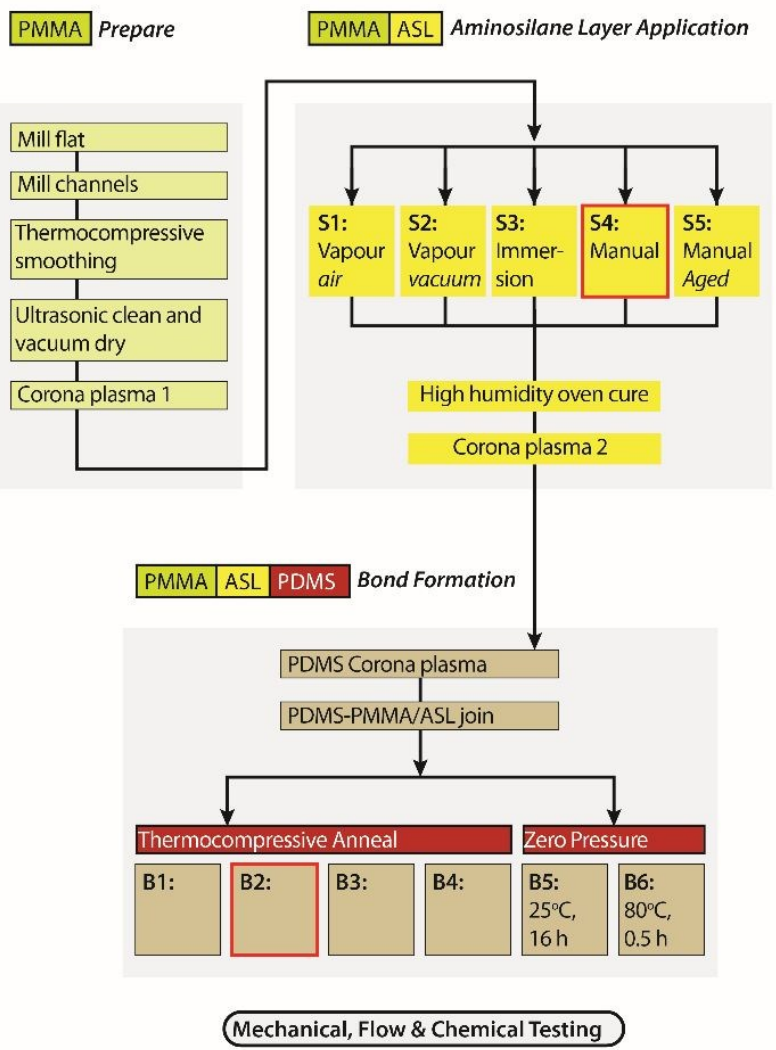

Fig. 3 Flowchart showing bonding process options.

Immersion tests in $1 \mathrm{M} \mathrm{NaOH}$ were performed by filling the channels and submerging the device in a petri glass of the solution, lidded to limit evaporation. Alternatively, device channels were filled with 0.3 $-1 \mathrm{M} \mathrm{NaOH}$, sealed and stored in a petri with water, for subsequent refill with DI prior to tape pull tests. Final devices were fabricated for further flow testing. Aqueous dye was input in constant pressure mode, using an Elveflow AF1 P1600 Pressure generator, which regulates air pressure, via a software interface, to a fluid filled glass reservoir at the input to the microfluidic device. The pressure generator had a stability of $0.05 \%$, and response time of $50 \mathrm{~ms}$.

\section{Results and Discussion.}


Ion leakage and $\mathrm{TCO}_{2}$ transfer tests.

Sets of 3 different samples each of PDMS $(50 \mu \mathrm{m})$, and porous PTFE (63 $\mu \mathrm{m}, 0.45 \mu \mathrm{m}$ pores), were tested for ion leakage from 12.88 $\mathrm{mS} / \mathrm{cm}$ solution into DI water, with the averaged results in Fig. 4. Single samples of semi-permeable PS, PP, PC, and LDPE were tested for longer term ion transfer, and since there was little difference between them, the results averaged into a single line, also in Fig. 4. Ion leakage through the semi-permeable thermoplastics and permeable PDMS is almost negligible as expected, providing no pinholes are present. Porous PTFE has previously been used as a membrane for $\mathrm{TCO}_{2}$ detection ${ }^{30}$. The graph for porous PTFE, even after 20 min diffusion time, suggests that ionic interference from $50 \mathrm{mS} / \mathrm{cm}$ seawater samples is likely to be very high and hence is unsuitable as a gas permeable seawater membrane.

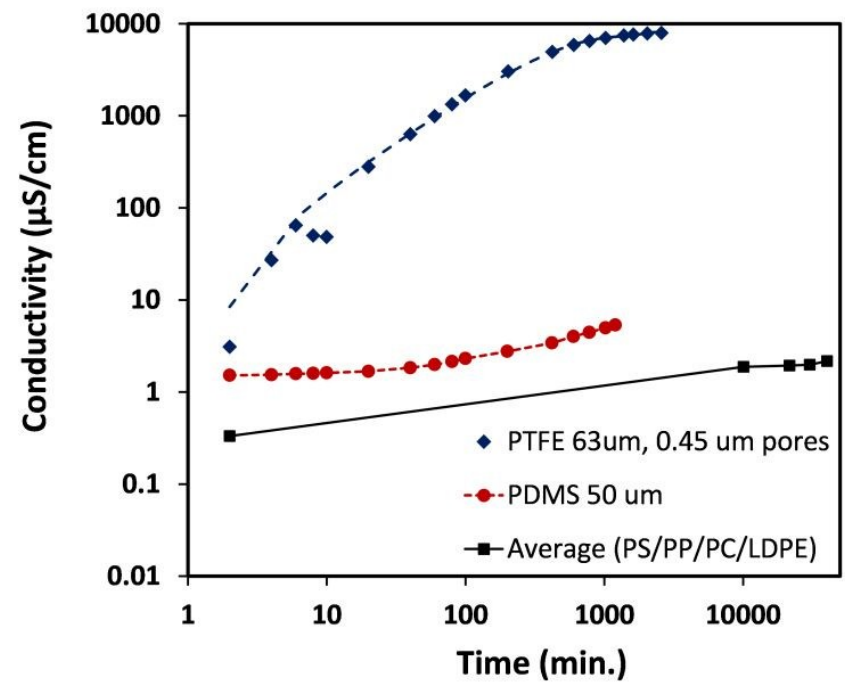

Fig. 4 lon leakage from $12.88 \mathrm{mS} / \mathrm{cm}$ solution into $\mathrm{DI}$, for various membrane materials. Conductivity errors are $\pm 0.1 \%$.

$\mathrm{TCO}_{2}$ transfer was measured by the decrease in $\mathrm{NaOH}$ conductivity, as the $\mathrm{CO}_{2}$ from the acidified bicarbonate solution diffused through the membrane. An average of measurements obtained from 3 membranes of each type are shown in, Fig. 5. The graph shows an initial time delay before the conductivity decreases due to gas diffusion through the PDMS membranes and subsequently to the conductivity sensor, situated $\sim 15 \mathrm{~mm}$ from the membrane. The difference in delay between $50 \mu \mathrm{m} / 125 \mu \mathrm{m}$ and $50 \mu \mathrm{m} / 450 \mu \mathrm{m}$ membranes is $12 \mathrm{~min}$ and $20 \mathrm{~min}$ respectively. This suggests a $\mathrm{CO}_{2}$ diffusion rate through the membrane of $7-20 \mathrm{~m} \mathrm{~min}^{-1}$. The rate of conductivity decrease is approximately constant for all PDMS thicknesses due to the significance of the diffusion time from membrane to sensor. However in a true microfluidic device, the fluid distance will be reduced by a factor of $\sim 100$ and hence the time required for sensor saturation will be of the order of $1-2 \mathrm{~min}$. A semi-permeable membrane of PC $(20 \mu \mathrm{m})$ shows $7 \mathrm{x}$ slower $\mathrm{CO}_{2}$ transport compared to the $50 \mu \mathrm{m}$ membrane, indicating its lack of suitability for gas permeation sensing. The rapid change in conductivity with porous PTFE membranes is likely to be dominated by ion exchange across the membrane rather than an indicator of
$\mathrm{CO}_{2}$ transport. Seawater conductivity is $\sim 50 \mathrm{mS} \mathrm{cm}^{-1}$, compared Apred to

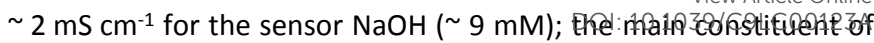
seawater, $\mathrm{NaCl}$, has a molarity of $\sim 600 \mathrm{mM}$, and this could be expected to flow rapidly through porous PTFE, increasing the conductivity on the $\mathrm{NaOH}$ side by $\sim 6$ times, and therefore masking any signal from $\mathrm{CO}_{2}$ diffusion. These results clearly show that $50 \mu \mathrm{m}$ PDMS outperforms porous PTFE and semi-permeable PC as a gas permeable membrane. The subsequent experiments, therefore, examined bonding of PDMS to PMMA patterned with microfluidic channels.

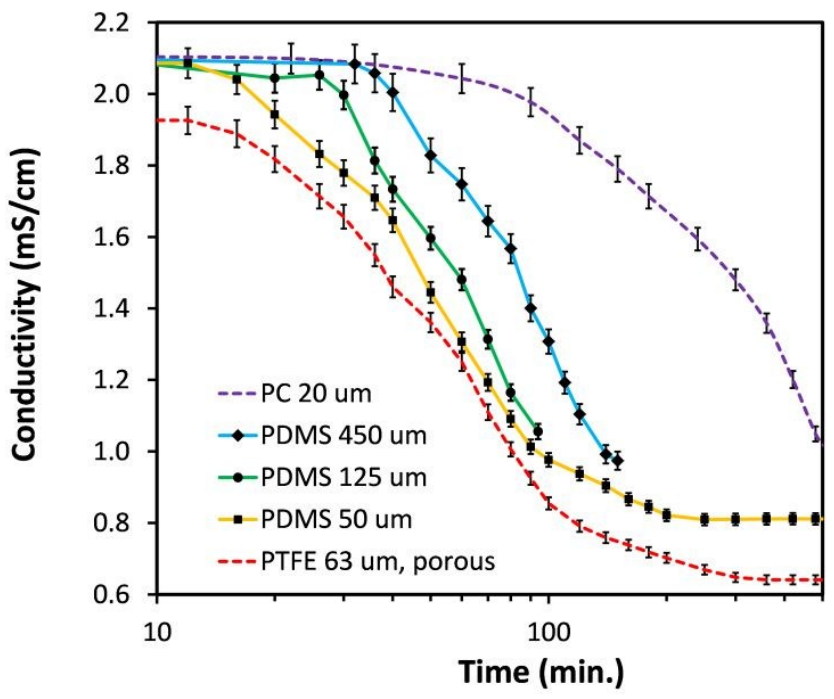

Fig. $5 \mathrm{TCO}_{2}$ transfer measured by decrease in $\mathrm{NaOH}$ solution conductivity. Error bars are between $\pm 2 \%-3 \%$, depending on the data sets.

\section{Process parameter and materials screening tests}

Given the very wide potential parameter space involving chemistry, application, annealing and plasma treatment options, we undertook a screening programme. Numerous process sequences were explored with the initial focus on silane chemistry A (APTES), B (BTMSPA) and mixed-silane $A B$, plus silane application parameters (S1 to S4 in Table 1) for various cure, bond and anneal regimes. After this stage, it was concluded that chemistry A and application methods S1 and S2 offered lower potential for success, so the dominant focus moved to silane chemistry $B$, via application methods S3 and S4. The challenge, therefore, is to apply and cure silane that is non-hydrolysed, smooth, and crack-free. Of the three main approaches, vapour exposure is slow and limited to nearmonolayer formation, while immersion in a silane solution has led to thick but uneven coatings. Manual application has inherent drawbacks but still offers a greater degree of control.

Plasma treatments and bond annealing offer a very wide range of process parameters which prevent systematic exploration. We have observed surface rearrangement and possible melting of PMMA subjected to $\mathrm{O}_{2}$ plasma, possibly because the local temperature overshoots the polymer $\mathrm{T}_{\mathrm{g}}$. Corona plasma is much less energetic and was considered preferable, especially for silane and PDMS treatments. We restricted corona plasma exposure to 8 minutes per 
$100 \mathrm{~mm} \times 100 \mathrm{~mm}$ substrate, which reduces the PMMA water contact angle from $\sim 80^{\circ}$ to $37^{\circ}$ (i.e. hydrophilic). Pressure application above $50{ }^{\circ} \mathrm{C}$ caused stress lines in regions of PDMS suspended over the channels. This is possibly due to pinning of the membrane by the bond and the channel edges coupled with a difference in thermal expansion coefficient between PDMS and silane. At temperatures from $80{ }^{\circ} \mathrm{C}-105{ }^{\circ} \mathrm{C}$, the $125 \mu \mathrm{m}$ PDMS under pressure distorts into the channels, but the $50 \mu \mathrm{m}$ thickness film remains unaffected. We explored the possibility of applying high pressure $(\mathrm{kN})$ at room temperature followed by manually incrementing the temperature to a maximum $80^{\circ} \mathrm{C}$, method $\mathrm{B} 4$ (Table 2). However no improvement in bond strength was observed. Methods B5 and B6 (Table 2) used zero force and were unsuccessful so no further tests were undertaken. Sample images, including some problem areas, are shown in Fig. 6(a) to $(f)$.

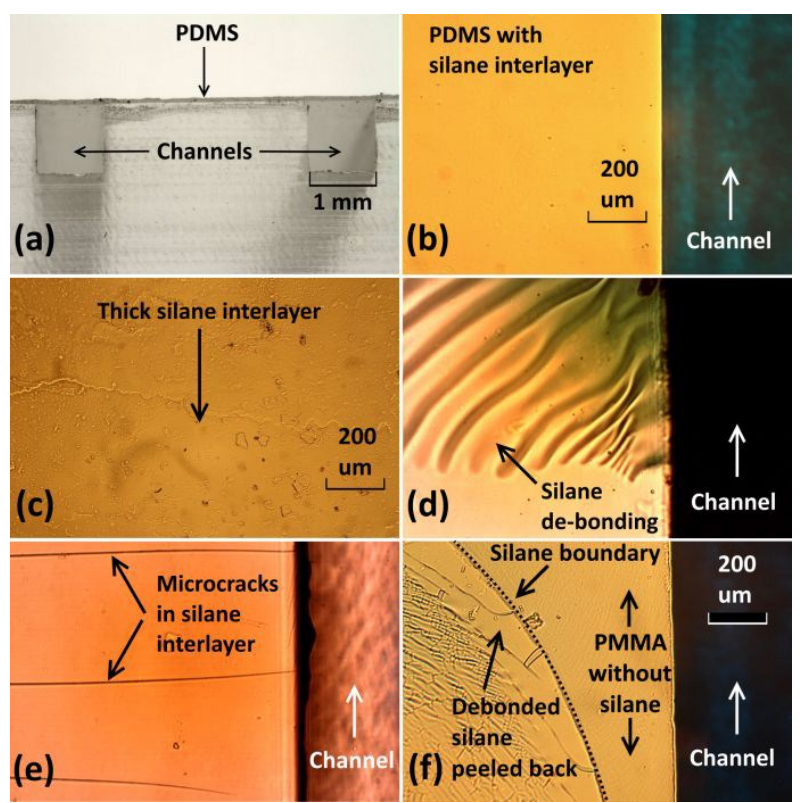

Fig. 6 Digital photographs as follows (a) PDMS membrane, $50 \mu \mathrm{m}$ thickness, bonded to PMMA with microchannels, using vapour-deposited APTES, (b) PDMS-sealed dye-filled channel, with thick silane coated to channel edges, (c) magnified view of thick silane applied using multiple coats, (d) failure of PDMS bond adhesion on the channel edge, shown by rippling of the silane and PDMS layers, (e) PDMS-sealed channel, where silane layers show a low density of microcracks terminating at the channel edge, (f) peel back of the PDMS/silane from channel edge, at a position of adhesion failure, showing the silane layer with microcracks remaining adhered to the PDMS, on the left hand side, while being cleanly detached from the PMMA in the centre of the image. The bond failure is at the silane:PMMA interface.

\section{Mechanical and Flow Testing}

Quantitative bond strength measurement is difficult with highly pliable PDMS. However, the strenuous nature of a tape pull test represents an exacting failure test methodology which amplifies any minor weaknesses. Bonded membranes over dye-filled channels were subjected to tape pull tests at various stages up to 36 hours after filling. A few devices failed almost immediately after channel fill, mainly those with aged silane coatings, or delayed manual compression of the joined pair after PDMS corona treatment. A small number also failed between 6 - 24 hours while the remainder survived at least 36 hours of liquid exposure, 19 reetản strength sufficient to resist the tape pull. In failed devices, delaminated PDMS membranes showed the bulk silane film had adhered to the PDMS only, suggesting the bond to the PMMA was being hydrolysed. Fig 7(a) shows tape pull initiated dye leakage from two channels. In failed devices, leakages occurred at random positions, uncorrelated with any visible condition before or after PDMS bonding.

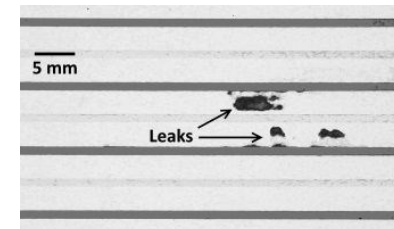

(a)

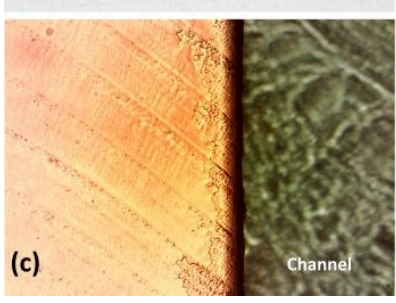

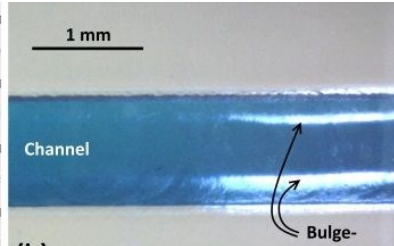

(b)

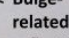
reflection

(d)

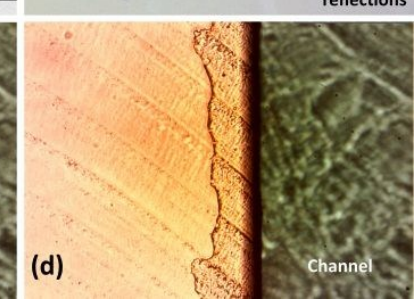

Fig. 7 (a) Tape-pull induced silane delamination visible as small leaks between channels, 24 hours after dye fill. (b) Membrane distortion under positive pressure as observed from linear reflections from underside LED illumination, (c) plan view of the bond interface, observed from above through transparent PDMS without DI water flow and (d) with DI water flow indicating minor lifting of the PDMS bond at channel edges due to fluid pressure, if not perfectly bonded.

The presence of residual surface water vapour prior to silane coating may allow hydrophilic methoxy groups on the silane molecule to orientate towards the substrate, giving a hydrolysable $\mathrm{Si}-\mathrm{O}-\mathrm{C}$ bond to the PMMA, instead of a hydrolytically resistant amide bond. ${ }^{39}$ However, substrate vacuum dehydration before silanation did not produce a significant improvement. BTMSPA was aged in IPA with a Ti Butoxide catalyst (S5 Table 1), to partially replace methoxy groups with longer propoxy groups, which should produce stearic hindrance to $\mathrm{H}_{2} \mathrm{O}$ penetration and slow the hydrolytic attack. However, in our case, the short-term aged solutions did not result in measureable improvement. Long-term aged solutions (1 week) showed increased density of micro-globules (consistent with hydrolysis) which often led to large areas of bond failure. In contrast, freshly prepared BTMSPA was relatively smooth when cured, if applied in a single coating.

Devices which had passed the 36 hour tape pull test were subjected to pressurised flow tests. The PDMS membrane bulges upwards during pressurised flow and this creates a large strain at the PDMSPMMA interface close to the channel edge, Fig. 7(b). The PDMS lifted upwards, without delamination, as the channel was pressurised, Fig. 7(c), (d). The magnitude of the PDMS peak deflection versus applied pressure, for a $1 \mathrm{~mm}$ wide channel, was measured optically and reached $160 \mu \mathrm{m}$ at $600 \mathrm{mBar}$, Fig. 8. This is much less that the $\sim 1 \mathrm{~mm}$ 
deflection produced by the tape pull test, indicating the aggressiveness of the latter. Peak flow rates were between $70-140$ $\mathrm{mL} \mathrm{min}^{-1}$ and the normalised flow rate versus pressure characteristics averaged for all device sets was close to linear up to $500 \mathrm{mbar}$, demonstrating bond integrity, see Fig. 8 .

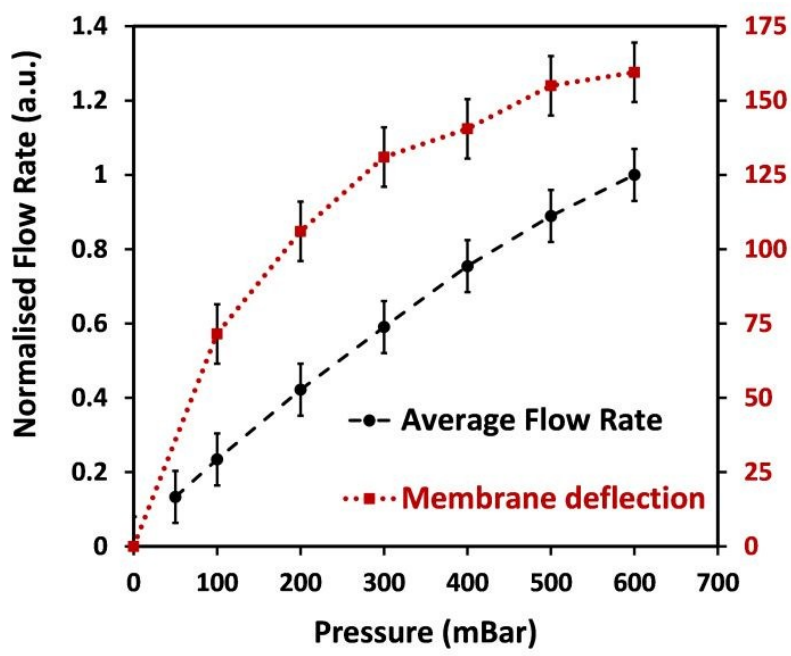

Fig. 8 Magnitude of PDMS deflection against pressure, and average flow rate versus pressure for 6 channels distributed over 4 devices. Error bars of \pm 10 $\mu \mathrm{m}$ are shown for the deflection data, and \pm 0.07 for the normalised flow rate data.

By blocking the channel output and ramping the pressure, burst pressures between $600 \mathrm{mBar}$ (for 1 minute) and $800 \mathrm{mBar}$ (for 20s) were observed, with delamination along the PMMA bond interface. The observed flow rates are similar in magnitude to those reported in the literature when the channel total internal volumes (TIV) are taken into account. For a typical TIV of $0.03 \mathrm{~mL}$ and average maximum flow rates of $90 \mathrm{~mL} \mathrm{~min}-1$, the volume $\mathrm{min}^{-1}$ is $~ 3000 \times$ TIV which is commensurate with values of $\sim 600 \times$ TIV $^{38}$ and $1000-$ $2000 \times$ TIV $^{37}$ previously reported for PDMS - thermoplastic bonding. For $C_{T}$ ocean profiling, sample capture every $10 \mathrm{~m}$ would be preferred. The Argo float travels at $<10 \mathrm{~m} \mathrm{~min}^{-1}$ and we estimate a volume requirement of up to $200 \mu \mathrm{L}$ per depth sample. Therefore a $10 \mathrm{~cm}$ depth resolution would require a flow rate of $\sim 2 \mathrm{~mL} \mathrm{~min}^{-1}$, much lower than the peak flow rates observed. The stress on the bond in a real device would therefore be much less in this particular application than under the current test regime.

\section{Chemical Resistance}

Chemical stability of the PDMS-silane-PMMA bond was investigated with different concentrations of $\mathrm{NaOH}$ via immersion and channel filling, with added dyes to aid observations. After $24 \mathrm{hr}$ exposure to undiluted $\mathrm{NaOH}(\sim 1 \mathrm{M})$, bond degradation is visible with complete delamination occurring after 3 days, Fig. 9(a). However the bond integrity remained intact against dilute solutions $(0.3-0.5 \mathrm{M})$, Fig. Fig. 9(b), (c). Long-term chemical resistance was determined via repeated tape pull tests for channels exposed to $0.01 \mathrm{M} \mathrm{NaOH}$ for $>$ 1 month. The best results were obtained for test set 2 devices where no interchannel leakage was observed for over $75 \%$ of channels tested. After 2 weeks and 6 weeks, the $\mathrm{NaOH}$ was replaced by $\mathrm{DI}$

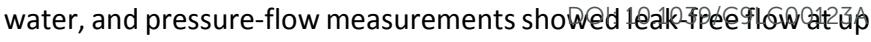
to $600 \mathrm{mBar}(85-100 \mathrm{~mL} / \mathrm{min})$.

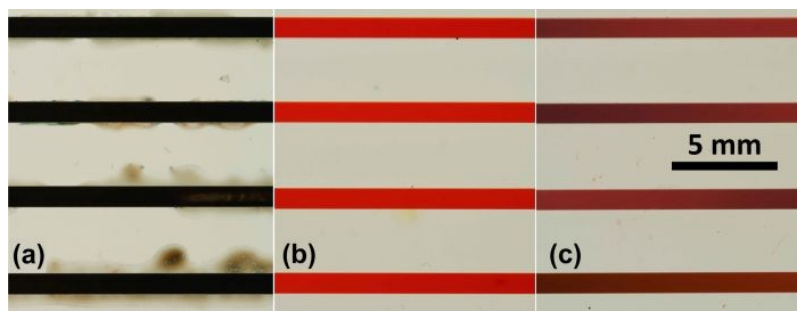

Fig. 9 Bond condition after 24 hours of filled channels with (a) $1 \mathrm{M} \mathrm{NaOH}$, (b) $0.5 \mathrm{M} \mathrm{NaOH}$ and (c) $0.3 \mathrm{M} \mathrm{NaOH}$.

Test set 2 device fabrication utilised a dilute 1:40 silane:IPA solution where excess fluid filled the channels. After removal of this fluid, the remaining aminosilane layer does not end at the channel edge but continues conformally into the channel and presents a protective barrier against chemical attack of the interface bond, see 10.

It is likely that the BTMSPA aminosilane layer has formed a strong amide bond with the PDMS, since it does not easily delaminate from it, as seen in Fig. 6(f). Such amide bonds are known to be hydrolytically stable. Conversely, it appears that the silane layer has formed weak hydrolysable bonds with the PMMA, since delamination occurs at that interface, when it is unprotected along the channel edges. Thin conformal coating within the channel however protects the silane layer from exposure to the $\mathrm{NaOH}$ reagent and long-term chemical resilience and leak-free open flow is achievable.

It should be noted that the PDMS will ultimately be bonded on top and bottom faces to PMMA with microchannels and as such will be subject to much lower bond stresses than in the open test structure used here to highlight any potential weakness.

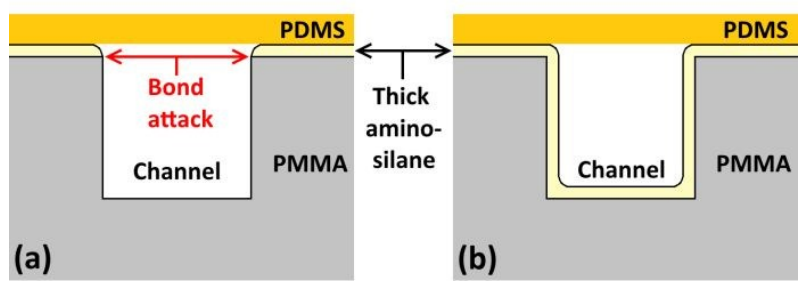

Fig. 10 (a) bond exposure to chemical attack for standard coating (test sets 1 , $3,4)$ and (b) bond protection for 42 days exposure to $\mathrm{NaOH}$, via conformal aminosilane coating of PMMA surface and channels.

\section{Conclusions}

Initially, we showed that PDMS is a preferred membrane for $\mathrm{CO}_{2}$ 
transfer from an acidified sample solution, without ion leakage. We then demonstrated high strength chemical resistant bonding of PDMS to thermoplastic (PMMA) manifolds which was able to withstand $\mathrm{NaOH}$ exposure over many weeks and strenuous tape pull tests. A wide range of processing parameters involving the deposition of aminosilane layers, plasma treatments and vacuum thermocompressive annealing were investigated. Vacuum compression required force as low as $200 \mathrm{~N}(20 \mathrm{kPa})$ at moderate temperatures $\left(80^{\circ} \mathrm{C}\right)$ below the polymer $\mathrm{T}_{\mathrm{g}}$. Silanation chemistries involving bipodal aminosilanes (e.g. BTMSPA), where the amine group is in the middle of the silane chain, were found to perform better than monopodal (e.g. APTES) or mixed layers. The method of aminosilane layer application is key to success. Both vapour treatments and total immersion proved problematic. However manual treatment including channel filling with dilute 1:40 silane:IPA followed by evaporation, led to conformal coating of the PMMA channel walls and surface with a protective aminosilane coating which provided a barrier between $\mathrm{NaOH}$ and the interface bonds. While manual treatments can involve unwanted variability, our proof of principle results point to more controllable techniques such as ultrasonic spraying, a common industrial technique for high quality thin coating of fine geometries. ${ }^{40}$ The demonstration of long-term stable membrane-based microfluidics is an important step in development of remote environmental chemical analysis devices. In particular, ocean carbon measurements using low power miniaturised conductimetric techniques become viable and open up possibilities for long sought continuous depth profiling of dissolved inorganic carbon.

\section{Acknowledgements}

The authors would like to acknowledge the funding support from Invest N. Ireland (RD0714186), the Department of Employment and Learning, N. Ireland (US-IRL 013), Science Foundation Ireland (09/US/I1758), and National Science Foundation (US) (NSF 0961250). We would also like to acknowledge Todd Martz and Phil Bresnahan of Scripps Institute of Oceanography for their support and encouragement through fruitful discussions on device design and test.

\section{Conflicts of Interest.}

There are no conflicts to declare.

\section{References}

1 www.ipcc.ch/report/ar5/index.shtml, (accessed 7/18/2016 2016).

2 C. L. Sabine, R. A. Feely, N. Gruber, R. M. Key, K. Lee, J. L. Bullister, R. Wanninkhof, C. S. Wong, D. W. R. Wallace, B. Tilbrook, F. J. Millero, T. -. Peng, A. Kozyr, T. Ono and A. F. Rios, Science, 2004, 305, 367-371 (DOI:10.1126/science.1097403).

3 J. L. Bamber and W. P. Aspinall, Nat. Clim. Change, 2013, 3, 424-427 (DOI:10.1038/nclimate1778).

4 www.socat.info, (accessed 7/18/2016 2016).
5 P. Bresnahan, T. Martz, J. deAlmeida, B. Ward and P. D.

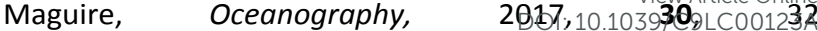
(DOI:10.5670/oceanog.2017.215).

6 A. J. deMello, Nature, 2006, 442, 394402 (DOI:10.1038/nature05062).

7 D. Mark, S. Haeberle, G. Roth, F. Von Stetten and R. Zengerle, Chem. Soc. Rev., 2010, 39, 1153-1182 (DOI:10.1039/b820557b).

8 F. J. Millero, Chem. Rev., 2007, 107, 308-341 (DOI:10.1021/cr0503557).

9 R. H. Byrne, Environ. Sci. Technol., 2014, 48, 5352-5360 (DOI:10.1021/es405819p).

10 http://www.argo.ucsd.edu/, (accessed 7/18/2016 2016).

11 F. -. Legiret, V. J. Sieben, E. M. S. Woodward, S. K. Abi Kaed Bey, M. C. Mowlem, D. P. Connelly and E. P. Achterberg, Talanta, 2013, 116, 382-387 (DOI:10.1016/j.talanta.2013.05.004).

12 I. R. Ogilvie, V. J. Sieben, M. C. Mowlem and H. Morgan, Anal. Chem., 2011, 83, 4814-4821 (DOI:10.1021/ac200463y).

13 M. Bowden and D. Diamond, Sens Actuators, B Chem, 2003, 90, 170-174 (DOI:10.1016/S0925-4005(03)00024-8).

14 A. D. Beaton, C. L. Cardwell, R. S. Thomas, V. J. Sieben, F. E. Legiret, E. M. Waugh, P. J. Statham, M. C. Mowlem and H. Morgan, Environ. Sci. Technol., 2012, 46, 9548-9556 (DOI:10.1021/es300419u).

15 M. Czugala, C. Fay, N. E. O'Connor, B. Corcoran, F. BenitoLopez and D. Diamond, Talanta, 2013, 116, 997-1004 (DOI:10.1016/j.talanta.2013.07.058).

16 I. M. Perez De Vargas Sansalvador, C. D. Fay, J. Cleary, A. M. Nightingale, M. C. Mowlem and D. Diamond, Sens Actuators, B Chem, 2016, 225, 369-376 (DOI:10.1016/j.snb.2015.11.057).

17 T. Fukuba, A. Miyaji, T. Okamoto, T. Yamamoto, S. Kaneda and T. Fujii, RSC Adv., 2011, 1, 1567-1573 (DOI:10.1039/c1ra00490e).

18 T. Fukuba, Y. Aoki, N. Fukuzawa, T. Yamamoto, M. Kyo and T. Fujii, Lab Chip Miniaturisation Chem. Biol., 2011, 11, 35083515 (DOI:10.1039/c1lc20523d).

19 C. Provin, T. Fukuba, K. Okamura and T. Fujii, IEEE J Oceanic Eng, 2013, 38, 178-185 (DOI:10.1109/JOE.2012.2208849).

20 G. E. Friederich, P. G. Brewer, R. Herlien and F. P. Chavez, Deep-Sea Res. Part I Oceanogr. Res. Pap., 1995, 42, 1175-1186 (DOI:10.1016/0967-0637(95)00044-7).

21 T. S. Moore, M. D. DeGrandpre, C. L. Sabine, R. C. Hamme, C. J. Zappa, W. R. McGillis, R. A. Feely and W. M. Drennan, J. Geophys. Res., 2011, 116, COOF11 (DOI:10.1029/2010JC006560).

22 M. D. DeGrandpre, T. R. Hammar, S. P. Smith and F. L. Sayles, Limnol. Oceanogr., 1995, 40, 969-975 (DOI:10.4319/lo.1995.40.5.0969).

23 Y. Nakano, H. Kimoto, S. Watanabe, K. Harada and Y. W. $\begin{array}{lllll}\text { Watanabe, J. Oceanogr., } & 2006, & 62, & 71 & 81\end{array}$ (DOI:10.1007/s10872-006-0033-y).

24 B. Fiedler, P. Fietzek, N. Vieira, P. Silva, H. C. Bittig and A. Körtzinger, J. Atmos. Ocean. Technol., 2013, 30, 112126 (DOI:10.1175/JTECH-D-12-00043.1).

25 X. Liu, R. H. Byrne, L. Adornato, K. K. Yates, E. Kaltenbacher, X. Ding and B. Yang, Environ. Sci. Technol., 2013, 47, 1110611114 (DOI:10.1021/es4014807).

26 Z. A. Wang, F. N. Sonnichsen, A. M. Bradley, K. A. Hoering, T. M. Lanagan, S. N. Chu, T. R. Hammar and R. Camilli, Environ. Sci. Technol., 2015, 49, 4441-4449 (DOI:10.1021/es504893n).

27 A. J. Fassbender, C. L. Sabine, N. Lawrence-Slavas, E. H. De Carlo, C. Meinig and S. Maenner Jones, Environ. Sci. Technol., 2015, 49, 3628-3635 (DOI:10.1021/es5047183)

28 R. J. Bell, R. T. Short and R. H. Byrne, Limnol. Oceanogr Methods, 2011, 9, 164-175 (DOI:10.4319/lom.2011.9.164). 
29 F. L. Sayles and C. Eck, Deep-Sea Res. Part I Oceanogr. Res. Pap., 2009, 56, 1590-1603 (DOI:10.1016/j.dsr.2009.04.006).

30 P. Hall and R. Aller, Limnol. Oceanogr., 1992, 37, 1113-1119 (DOI:10.4319/lo.1992.37.5.1113).

31 J. N. Plant, K. S. Johnson, J. A. Needoba and L. J. Coletti, Limnol. Oceanogr. Methods, 2009, 7, 144-156 (DOI:10.4319/lom.2009.7.144).

32 D. Sun, M. Tweedie, D. R. Gajula, B. Ward and P. D. Maguire, $\begin{array}{ll}\text { Microfluid. Nanofluid., 2015, 19, 913-922 } & \end{array}$ (DOI:10.1007/s10404-015-1620-2).

33 J. De Jong, R. G. H. Lammertink and M. Wessling, Lab Chip Miniaturisation Chem. Biol., 2006, 6, 1125-1139 (DOI:10.1039/b603275c).

34 V. Sunkara and Y. K. Cho, ACS Appl. Mater. Interfaces, 2012, 4, 6537-6544 (DOI:10.1021/am3015923).

35 V. Sunkara, D. -. Park, H. Hwang, R. Chantiwas, S. A. Soper and Y. -. Cho, Lab Chip Miniaturisation Chem. Biol., 2011, 11, $962-$ 965 (DOI:10.1039/c0lc00272k).

36 P. Gu, K. Liu, H. Chen, T. Nishida and Z. H. Fan, Anal. Chem., 2011, 83, 446-452 (DOI:10.1021/ac101999w).

37 L. Tang and N. Y. Lee, Lab Chip Miniaturisation Chem. Biol., 2010, 10, 1274-1280 (DOI:10.1039/b924753j).

38 J. Wu and N. Y. Lee, Lab Chip Miniaturisation Chem. Biol., 2014, 14, 1564-1571 (DOI:10.1039/c3lc51324f).

39 K. S. Lee and R. J. Ram, Lab Chip Miniaturisation Chem. Biol., 2009, 9, 1618-1624 (DOI:10.1039/b820924c).

40 M. Buck, Method for Applying an Adhesion Promoter Composition by Means of an Ultrasonic Atomizer, 20090068477 A1, US, 2009.

41 K. Haubert, T. Drier, D. Beebe, Technical Note, Lab Chip, 2006, 6, 1548-1549 (DOI:10.1039/B610567J).

42 K. Liu, P. Gu, K. Hamaker, Z. H. Fan, J Colloid Interface Sci. 365, 2012 289-295 (DOI:10.1016/j.jcis.2011.09.004).

43 M. A. Eddings M. A. Johnson, B. K. Gale, J. Micromech. Microeng. 18 (2008) 067001 (4pp) (DOI:10.1088/0960$1317 / 18 / 6 / 067001)$.

44 H. Y. Tan, W. K. Loke, N. T. Nguyen, Sens. Act. B, 151 (2010) $133-139$ (DOI:10.1016/j.snb.2010.09.035).

45 W. W. Y. Chow, K. F. Lei, G. Shi, W. J. Li, Q. Huang, Smart Mater. Struct. 15, 2006, S112-S116 (DOI:10.1088/09641726/15/1/018).

46 K. Kim, S. W. Park, S. S. Yang, BioChip J. (2010) 4(2): 148-154 (DOI 10.1007/s13206-010-4210-0).

47 Strong, J., Publ. A.S.P, Vol. 46, 1934.

48 K. L. Mittal, Adhesion measurement of thin films, Electrocomponent Science and Technology, 1976, Vol. 3, pp. 21-42.

49 B. Moazzez, S.M. O'Brien and E.F. Merschrod S., Improved Adhesion of Gold Thin Films Evaporated on Polymer Resin: Applications for Sensing Surfaces and MEMS, Sensors, 2013, 13, 7021-7032, DOI:10.3390/s130607021. 